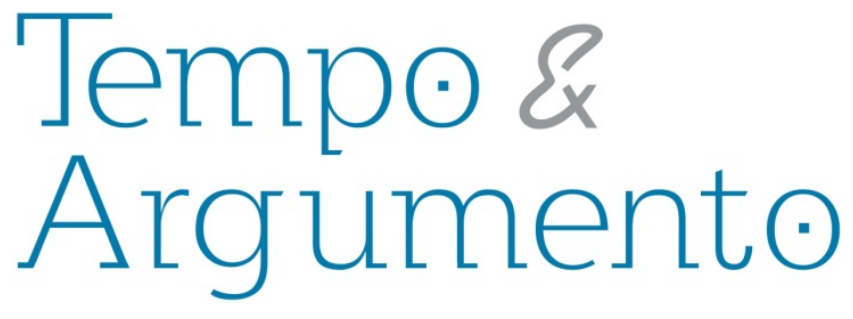

\title{
Cena cosplay: comunicação, consumo, memória nas culturas juvenis
}

\section{Resenha da obra:}

Cena cosplay: comunicação, consumo, memória nas culturas juvenis/ organizado por Mônica Rebecca Ferrari Nunes. - - Porto Alegre: Sulina, 2015.

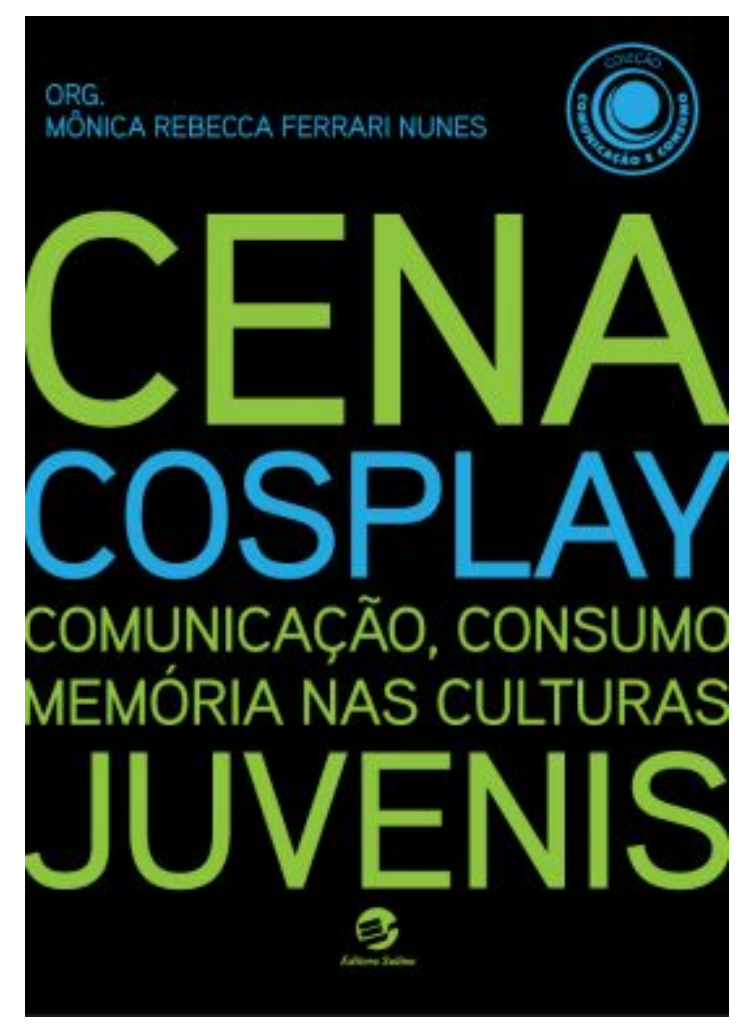

\section{Autora da resenha}

\section{Rosana da Silva Cuba}

Doutoranda no Programa de Pós-Graduação em Educação da Universidade Federal de Santa Catarina. Brasil rosana.cuba32@gmail.com

\section{Para citar esta resenha:}

CUBA, Rosana da Silva. Cena cosplay: comunicação, consumo, memória nas culturas juvenis. Revista Tempo e Argumento, Florianópolis, v. 8, n. 18, p. 457 - 462. maio/abr. 2016. 
O último Estado da Arte sobre a temática da(s) juventude(s) na produção da pósgraduação brasileira, nas áreas de Educação, Ciências Sociais e Serviço Social foi publicado em 2009 e coordenado por Marília Sposito. Na época, a autora celebra o aumento das pesquisas sobre as juventudes, mas ressalta a necessidade de abarcar os jovens em suas múltiplas inserções: para além dos seus itinerários formativos escolares é possível empreender investigações numa perspectiva mais transversal e compreender como se dão as sociabilidades juvenis na rua, em suas intersecções e atuações em grupos religiosos e família, enfim, abarcar os diversos aspectos que compõem a vida cotidiana juvenil. Neste sentido, o livro organizado por Mônica Rebecca Ferrari Nunes, intitulado “Cena Cosplay: comunicação, consumo, memórias nas culturas juvenis” contribui para enriquecer o mosaico das pesquisas sobre jovens ao conjugar, em diferentes espaços e tempos, as categorias empíricas para uma compreensão dos jovens e a sua inserção no espaço urbano nas grandes cidades do sudeste do Brasil.

Mônica Rebecca Ferrari Nunes é docente e pesquisadora do Programa de PósGraduação em Comunicação e Práticas de Consumo, da Escola Superior de Propaganda e Marketing (ESPM), na cidade de São Paulo. Sua área de atuação envolve as áreas de comunicação, nas interfaces de produção midiática, cultura do consumo, processos de memória e cenas da cultura contemporânea.

O livro, segundo a autora, é uma proposta de cartografia, ainda que incompleta, sobre a prática cosplay entendida na tríade prática comunicativa, cultura e consumo. $\mathrm{O}$ livro é resultado de trabalho desenvolvido em grupo de estudos (Grupo de Pesquisa, Comunicação, Consumo e Entretenimento) da ESPM e vinculado ao CNPQ, e é organizado em seis partes: Cosplayers e poetas; Percepção, cognição e pertencimento; Moda e estilo urbano; Matérias sonoras; Games e colecionismo; Flânerie. Os textos que compõem a obra são de pesquisadores vinculados ao Grupo de Pesquisa e situados em diversos percursos acadêmicos, desde mestrandos a pós-doutores, imbuídos de um olhar comum: entender as relações dos jovens do Sudeste do Brasil com o cosplay, suas escolhas pelas representações, a relação com o consumo e a memória que se deseja construir. 
A primeira parte é composta por dois trabalhos, de autoria da organizadora Mônica Rebecca Ferrari Nunes - e de Marco Antônio Bin. Os dois textos versam sobre a compreensão da cena cosplay e da poesia marginal como formas de resistência ao cotidiano, materializadas em performances, sejam elas constituídas pelo prazer de encenar e pela captura dos ídolos para se fazerem ver e ouvir - caso dos cosplayers - ou pela ruptura com as mídias tradicionais e busca de uma visibilidade coletiva - caso dos poetas marginais. Os dois textos denotam para a necessidade de uma compreensão do cosplay juvenil como uma manifestação processual e cultural híbrida, entrelaçando formas de sociabilidades e constituição de identidades e fugindo de um olhar maniqueísta, segundo o qual os jovens cosplayers seriam meros consumidores e/ou reprodutores de ídolos midiáticos.

A segunda parte apresenta dois trabalhos que buscam se debruçar sobre as escolhas dos jovens que desejam e optam por serem cosplayers e a consciência que têm de si mesmos e de seus corpos. Ana Maria Guimarães Jorge e Gabriel Theodoro Soares assinalam o quanto o cosplay deve ser como interpretado não só como prática social, mas também como manifestação social, na medida em que o processo de constituição das identidades na contemporaneidade é marcado pela liquidez (Bauman, 2004). Assim o cosplay é uma possibilidade de constituir grupos para compartilhar vivências e, ainda, escolher representar um personagem que corresponda a determinados valores e significados com os quais há afinidade. Os dois textos constatam a relação entre o cosplay e a busca por um sentido à vida, numa espécie de jogo que propicia um tipo de fuga à vida cotidiana e promove o encontro consigo mesmo e com os seus pares. Essa fuga, contudo, não seria simplesmente fugir à ordem social vivida, mas a construção de outro espaço-tempo com uma ordem própria e condições de pertencimento.

A terceira parte compõe-se de dois textos que tratam sobre moda e sobre como o estilo cosplay influencia e se expande para outros campos. O texto de Tatiana Amendola Sanches aponta vários exemplos de apropriação, por parte de grandes marcas, de estratégias similares aos cosplayers, com modelos vestidos de determinados personagens. Michiko Okano, por sua vez, apresenta as características da "Lolita", prática que é definida pelos participantes muito mais como um estilo de vida do que 
como uma subcultura ou cosplayers, seja no Japão ou no Brasil. São analisadas as particularidades e o que há de comum em Lolitas nos dois países e salienta-se que há processos ambíguos que conjugam espetacularização, contestação e a procura de lugar e identificação em uma sociedade que se mostra hostil. As autoras destacam a articulação de consumo e ludicidade que parece constituir-se numa resistência ao mundo adulto e moderno desencantado.

A quarta parte, intitulada Matérias sonoras traz as contribuiçõos de Luiz Fukushiro e Heloísa de Araújo Duarte Valente, em texto que discute a presença da música no universo cosplay: muitos dos cosplayers, ao se apresentarem, adquirem, não apenas as vestimentas, mas, também, as vozes dos seus personagens. Além das vozes, a música constitui-se num elemento chave dos eventos cosplay, e, embora o mercado, de forma geral, não aceite o j-pop (uma apropriação japonesa do pop do Ocidente), ele é abarcado pelos cosplayers. Vera da Cunha Pasqualin, no texto seguinte, destaca o quanto é importante atentar-se para as onomatopéias maciçamente presentes nos mangás e tão importantes quanto as imagens para a compreensão do texto. A autora também analisa as performances de "vocaloides": pessoas que utilizam um programa para computadores denominado Vocaloid, com vozes gravadas e que podem ser recombinadas, para se apresentarem e cantarem em uma língua que não conseguiriam falar, por exemplo.

A penúltima parte é formada pelos textos de Davi Naraya Basto de Sá e Wagner Alexandre Silva, em torno da temática dos games e do colecionismo. Sá analisa o quanto os games redefinem a memória da mitologia, atualizando estereótipos em um processo constante de reedição. O autor também faz referência à constituição identitária daqueles cosplayers que escolhem determinados personagens: as pessoas são aquilo que desejam consumir. Silva irá mostrar como o colecionismo ligado aos cosplayers difere, em certa medida, da tradição das coleções já estudada pelo filósofo Benjamin. A aquisição dos objetos ocorre também por seus usos e aproximações com determinado personagem, pavimentando a relação de transição de cosplayer a colecionador, relação esta que pode tornar-se mais estreita quando se aumentam os cosplayers que se deseja assumir. 
A sexta parte, Flânerie, propõe um passeio por fotografias feitas pelos pesquisadores ao longo de suas pesquisas.

O livro pode ser comparado, imageticamente, a um caleidoscópio que fornece combinações diversificadas à luz do cosplay. Além de proporcionar um aprofundamento ao universo cosplay juvenil presente na região Sudeste do Brasil, contribui para pensar também nas metodologias para se estudar as juventudes. A organizadora cita, por exemplo, a experiência de ter entrevistado duas pessoas que fazem cosplayers via Facebook. Ainda, apresenta uma alternativa à Antropologia, área na qual não tem formação, combinando uma flanêrie e um "engajamento narrativo" com origem em Benjamin e, posteriormente, McLaren.

Por fim, a obra também contribui para debater o consumo na contemporaneidade e o quanto é preciso calibrar o olhar ao debruçar-se sobre a semiosfera cosplay: em tempos modernos - ou pós-modernos - já não é possível compreender as culturas juvenis e a sua relação com o consumo buscando uma motivação linear e unívoca. Temos sujeitos de habitus (Bourdieu) híbridos e, portanto, com identidades que se mesclam e metamorfoseiam, confundindo olhares mais aligeirados.

\section{Referências}

NUNES, Mônica Rebecca Ferrari (org.). Cena cosplay: comunicação, consumo, memória nas culturas juvenis. Porto Alegre: Sulina, 2015.

SPOSITO, Marilia Pontes (coord.) Estado da arte sobre juventude na pós-graduação brasileira: educação, ciências sociais e serviço social (1999-2006), volume 1. Belo Horizonte, MG: Argvmentvm, 2009. 
Recebido em 09/08/2016 Aprovado em 30/08/2016

Universidade do Estado de Santa Catarina - UDESC

Programa de Pós-Graduação em História - PPGH

Revista Tempo e Argumento Volume 08 - Número 18 - Ano 2016 tempoeargumento@gmail.com 